\title{
An updated overview of e-cigarette impact on human health
}

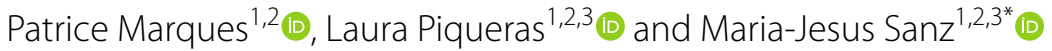

\begin{abstract}
The electronic cigarette (e-cigarette), for many considered as a safe alternative to conventional cigarettes, has revolutionised the tobacco industry in the last decades. In e-cigarettes, tobacco combustion is replaced by e-liquid heating, leading some manufacturers to propose that e-cigarettes have less harmful respiratory effects than tobacco consumption. Other innovative features such as the adjustment of nicotine content and the choice of pleasant flavours have won over many users. Nevertheless, the safety of e-cigarette consumption and its potential as a smoking cessation method remain controversial due to limited evidence. Moreover, it has been reported that the heating process itself can lead to the formation of new decomposition compounds of questionable toxicity. Numerous in vivo and in vitro studies have been performed to better understand the impact of these new inhalable compounds on human health. Results of toxicological analyses suggest that e-cigarettes can be safer than conventional cigarettes, although harmful effects from short-term e-cigarette use have been described. Worryingly, the potential long-term effects of e-cigarette consumption have been scarcely investigated. In this review, we take stock of the main findings in this field and their consequences for human health including coronavirus disease 2019 (COVID-19).
\end{abstract}

Keywords: Electronic cigarette, E-cigarette, Nicotine, Tobacco, Humectants, Flavourings, Toxicity, Smoking cessation tool, COVID-19

\section{Background}

Electronic nicotine dispensing systems (ENDS), commonly known as electronic cigarettes or e-cigarettes, have been popularly considered a less harmful alternative to conventional cigarette smoking since they first appeared on the market more than a decade ago. E-cigarettes are electronic devices, essentially consisting of a cartridge, filled with an $e$-liquid, a heating element/atomiser necessary to heat the e-liquid to create a vapour that can be inhaled through a mouthpiece, and a rechargeable battery (Fig. 1) [1, 2]. Both the electronic devices and the different e-liquids are easily available in shops or online stores.

*Correspondence: maria.j.sanz@uv.es

1 Department of Pharmacology, Faculty of Medicine, University of Valencia, Avda. Blasco Ibañez 15, 46010 Valencia, Spain

Full list of author information is available at the end of the article
The e-liquid typically contains humectants and flavourings, with or without nicotine; once vapourised by the atomiser, the aerosol (vapour) provides a sensation similar to tobacco smoking, but purportedly without harmful effects [3]. However, it has been reported that the heating process can lead to the generation of new decomposition compounds that may be hazardous $[4,5]$. The levels of nicotine, which is the key addictive component of tobacco, can also vary between the commercially available e-liquids, and even nicotine-free options are available. For this particular reason, e-cigarettes are often viewed as a smoking cessation tool, given that those with nicotine can prevent smoking craving, yet this idea has not been fully demonstrated $[2,6,7]$.

Because e-cigarettes are combustion-free, and because most of the damaging and well-known effects of tobacco are derived from this reaction, there is a common and widely spread assumption that e-cigarette consumption original author(s) and the source, provide a link to the Creative Commons licence, and indicate if changes were made. The images or other third party material in this article are included in the article's Creative Commons licence, unless indicated otherwise in a credit line to the material. If material is not included in the article's Creative Commons licence and your intended use is not permitted by statutory regulation or exceeds the permitted use, you will need to obtain permission directly from the copyright holder. To view a copy of this licence, visit http://creativecommons.org/licenses/by/4.0/. The Creative Commons Public Domain Dedication waiver (http://creativeco mmons.org/publicdomain/zero/1.0/) applies to the data made available in this article, unless otherwise stated in a credit line to the data. 
(See figure on next page.)

Fig. 1 Effect of the heating process on aerosol composition. Main harmful effects documented. Several compounds detected in e-cigarette aerosols are not present in e-liquids and the device material also seems to contribute to the presence of metal and silicate particles in the aerosols. The heating conditions especially on humectants, flavourings and the low-quality material used have been identified as the generator of the new compounds in aerosols. Some compounds generated from humectants (propylene glycol and glycerol) and flavourings, have been associated with clear airways impact, inflammation, impairment of cardiovascular function and toxicity. In addition, some of them are carcinogens or potential carcinogens

or "vaping" is safer than conventional cigarette smoking. However, are they risk-free? Is there sufficient toxicological data on all the components employed in e-liquids? Do we really know the composition of the inhaled vapour during the heating process and its impact on health? Can e-cigarettes be used to curb tobacco use? Do their consumption impact on coronavirus disease 2019 (COVID19)? In the present review, we have attempted to clarify these questions based on the existing scientific literature, and we have compiled new insights related with the toxicity derived from the use of these devices.

\section{Effect of e-cigarette vapour versus conventional cigarette exposure: in vivo and in vitro effects}

Numerous studies have been performed to evaluate the safety/toxicity of e-cigarette use both in vivo and in in vitro cell culture.

One of the first studies in humans involved the analysis of 9 volunteers that consumed e-cigarettes, with or without nicotine, in a ventilated room for $2 \mathrm{~h}$ [8]. Pollutants in indoor air, exhaled nitric oxide (NO) and urinary metabolite profiles were analysed. The results of this acute experiment revealed that $e$-cigarettes are not emission-free, and ultrafine particles formed from propylene glycol (PG) could be detected in the lungs. The study also suggested that the presence of nicotine in e-cigarettes increased the levels of NO exhaled from consumers and provoked marked airway inflammation; however, no differences were found in the levels of exhaled carbon monoxide (CO), an oxidative stress marker, before and after e-cigarette consumption [8]. A more recent human study detected significantly higher levels of metabolites of hazardous compounds including benzene, ethylene oxide, acrylonitrile, acrolein and acrylamide in the urine of adolescent dual users (e-cigarettes and conventional tobacco consumers) than in adolescent e-cigarette-only users (Table 1) [9]. Moreover, the urine levels of metabolites of acrylonitrile, acrolein, propylene oxide, acrylamide and crotonaldehyde, all of which are detrimental for human health, were significantly higher in e-cigarette-only users than in non-smoker controls, reaching up to twice the registered values of those from non-smoker subjects (Table 1) [9]. In line with these observations, dysregulation of lung homeostasis has been documented in non-smokers subjected to acute inhalation of e-cigarette aerosols [10].

Little is known about the effect of vaping on the immune system. Interestingly, both traditional and e-cigarette consumption by non-smokers was found to provoke short-term effects on platelet function, increasing platelet activation (levels of soluble CD40 ligand and the adhesion molecule P-selectin) and platelet aggregation, although to a lesser extent with e-cigarettes [11]. As found with platelets, the exposure of neutrophils to $e$-cigarette aerosol resulted in increased CD11b and CD66b expression being both markers of neutrophil activation [12]. Additionally, increased oxidative stress, vascular endothelial damage, impaired endothelial function, and changes in vascular tone have all been reported in different human studies on vaping [13-17]. In this context, it is widely accepted that platelet and leukocyte activation as well as endothelial dysfunction are associated with atherogenesis and cardiovascular morbidity [18, 19]. In line with these observations the potential association of daily e-cigarettes consumption and the increased risk of myocardial infarction remains controversial but benefits may occur when switching from tobacco to chronic e-cigarette use in blood pressure regulation, endothelial function and vascular stiffness (reviewed in [20]). Nevertheless, whether or not e-cigarette vaping has cardiovascular consequences requires further investigation.

More recently, in August 2019, the US Centers for Disease Control and Prevention (CDC) declared an outbreak of the e-cigarette or vaping product use-associated lung injury (EVALI) which caused several deaths in young population (reviewed in [20]). Indeed, computed tomography (CT scan) revealed local inflammation that impaired gas exchange caused by aerosolised oils from e-cigarettes [21]. However, most of the reported cases of lung injury were associated with use of e-cigarettes for tetrahydrocannabinol (THC) consumption as well as vitamin E additives [20] and not necessarily attributable to other e-cigarette components.

On the other hand, in a comparative study of mice subjected to either lab air, e-cigarette aerosol or cigarette smoke (CS) for 3 days (6 h-exposure per day), those exposed to e-cigarette aerosols showed significant increases in interleukin (IL)-6 but normal lung parenchyma with no evidence of apoptotic activity or 


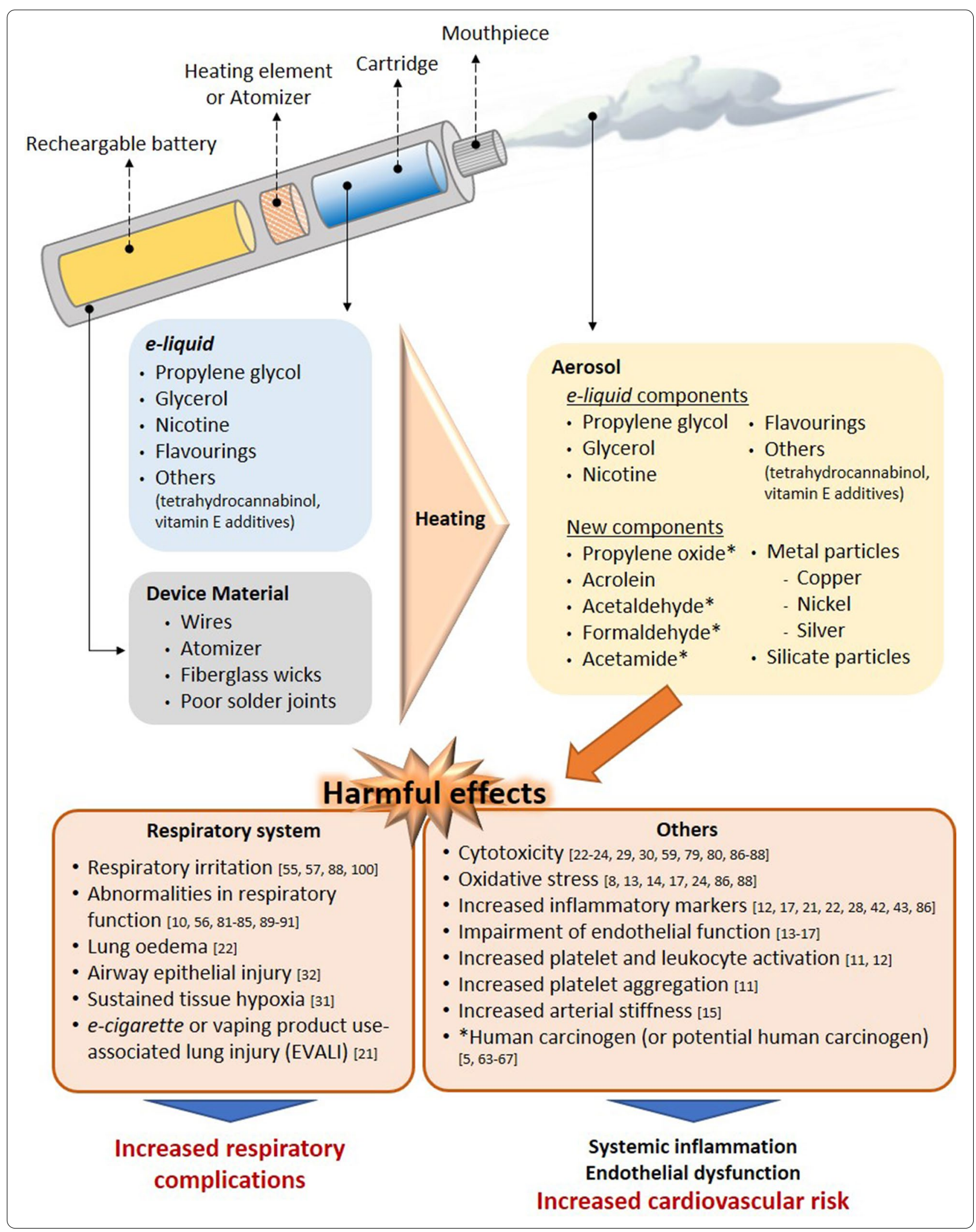


Table 1 Urine levels of metabolites of hazardous compounds in e-cigarette-only users versus dual users and non-smokers

\begin{tabular}{|c|c|c|c|c|c|c|}
\hline \multirow[t]{2}{*}{ Hazardous compounds } & \multicolumn{2}{|c|}{ E-Cigarette-only users } & \multicolumn{2}{|c|}{ Dual users } & \multicolumn{2}{|c|}{ Non-smoker controls } \\
\hline & Median & Range & Median & Range & Median & Range \\
\hline PMA (ng/mg of creatinine; benzene) & 0 & $0-2.0$ & $0.2^{* *}$ & $0-2.4$ & 0 & $0-0.1$ \\
\hline HEMA (ng/mg of creatinine; ethylene oxide) & 0.5 & $0-7.6$ & $1.0^{*}$ & $0-8.2$ & 1.3 & $0-4.0$ \\
\hline CNEMA (ng/mg of creatinine; acrylonitrile) & 1.3 & $0-108.4$ & $59.4^{* *}$ & $3.7-142.6$ & $0^{* *}$ & $0-1.6$ \\
\hline 3-HPMA (ng/mg of creatinine; acrolein) & 254.3 & $0-2311.6$ & $439.7^{*}$ & $153.6-814.4$ & $192.8^{*}$ & $0-1416.4$ \\
\hline 2-HPMA (ng/mg of creatinine; propylene oxide) & 28.8 & $0-1382.6$ & 40.2 & $10.2-310.9$ & $15.2^{* *}$ & $0-34.5$ \\
\hline AAMA (ng/mg of creatinine; acrylamide) & 67.3 & $0-581.2$ & $235.6^{* *}$ & $41.4-574.7$ & $34.5^{* *}$ & $0-182.0$ \\
\hline HMPMA (ng/mg of creatinine; crotonaldehyde) & 148.7 & 0-793.4 & 185.4 & $110.0-437.9$ & $100.4^{*}$ & $0-522.1$ \\
\hline
\end{tabular}

The concentrations of metabolites were normalised to creatinine values. PMA phenylmercapturic acid (metabolite of benzene), HEMA 2-hydroxyethylmercapturic acid (metabolite of ethylene oxide), CNEMA 2 cyanoethylmercapturic acid (metabolite of acrylonitrile), 3-HPMA 3 hydroxypropylmercapturic acid (metabolite of acrolein), 2-HPMA 2-hydroxypropylmercapturic acid (metabolite of propylene oxide), AAMA 2-carbamoylethylmercapturic acid (metabolite of acrylamide), HMPMA 3-hydroxy-1methylpropylmercapturic acid (metabolite of crotonaldehyde)

${ }^{*} \mathrm{P}<0.05$ or ${ }^{* *} \mathrm{P}<0.01$ versus e-cigarette-only users' group. Data adapted from Rubinstein et al. [9]

elevations in IL-1 $\beta$ or tumour necrosis factor- $\alpha$ (TNF $\alpha)$ [22]. By contrast, animals exposed to CS showed lung inflammatory cell infiltration and elevations in inflammatory marker expression such as IL-6, IL-1 $\beta$ and TNF $\alpha$ [22]. Beyond airway disease, exposure to aerosols from e-liquids with or without nicotine has also been also associated with neurotoxicity in an early-life murine model [23].

Results from in vitro studies are in general agreement with the limited number of in vivo studies. For example, in an analysis using primary human umbilical vein endothelial cells (HUVEC) exposed to 11 commerciallyavailable vapours, 5 were found to be acutely cytotoxic, and only 3 of those contained nicotine [24]. In addition, 5 of the 11 vapours tested (including 4 that were cytotoxic) reduced HUVEC proliferation and one of them increased the production of intracellular reactive oxygen species (ROS) [24]. Three of the most cytotoxic vapours-with effects similar to those of conventional high-nicotine CS extracts-also caused comparable morphological changes [24]. Endothelial cell migration is an important mechanism of vascular repair than can be disrupted in smokers due to endothelial dysfunction $[25,26]$. In a comparative study of CS and e-cigarette aerosols, Taylor et al. found that exposure of HUVEC to $e$-cigarette aqueous extracts for $20 \mathrm{~h}$ did not affect migration in a scratch wound assay [27], whereas equivalent cells exposed to CS extract showed a significant inhibition in migration that was concentration dependent [27].

In cultured human airway epithelial cells, both e-cigarette aerosol and CS extract induced IL-8/CXCL8 (neutrophil chemoattractant) release [28]. In contrast, while CS extract reduced epithelial barrier integrity (determined by the translocation of dextran from the apical to the basolateral side of the cell layer), e-cigarette aerosol did not, suggesting that only CS extract negatively affected host defence [28]. Moreover, Higham et al. also found that e-cigarette aerosol caused IL-8/CXCL8 and matrix metallopeptidase 9 (MMP-9) release together with enhanced activity of elastase from neutrophils [12] which might facilitate neutrophil migration to the site of inflammation [12].

In a comparative study, repeated exposure of human gingival fibroblasts to CS condensate or to nicotine-rich or nicotine-free e-vapour condensates led to alterations in morphology, suppression of proliferation and induction of apoptosis, with changes in all three parameters greater in cells exposed to CS condensate [29]. Likewise, both e-cigarette aerosol and CS extract increased cell death in adenocarcinomic human alveolar basal epithelial cells (A549 cells), and again the effect was more damaging with CS extract than with e-cigarette aerosol (detrimental effects found at $2 \mathrm{mg} / \mathrm{mL}$ of CS extract vs. $64 \mathrm{mg} /$ $\mathrm{mL}$ of e-cigarette extract) [22], which is in agreement with another study examining battery output voltage and cytotoxicity [30].

All this evidence would suggest that e-cigarettes are potentially less harmful than conventional cigarettes (Fig. 2) [11, 14, 22, 24, 27-29]. Importantly, however, most of these studies have investigated only short-term effects [10, 14, 15, 22, 27-29, 31, 32], and the long-term effects of e-cigarette consumption on human health are still unclear and require further study.

\section{Consequences of nicotine content}

Beyond flavour, one of the major issues in the e-liquid market is the range of nicotine content available. Depending on the manufacturer, the concentration of this alkaloid can be presented as low, medium or high, or expressed as $\mathrm{mg} / \mathrm{mL}$ or as a percentage $(\% \mathrm{v} / \mathrm{v})$. The 


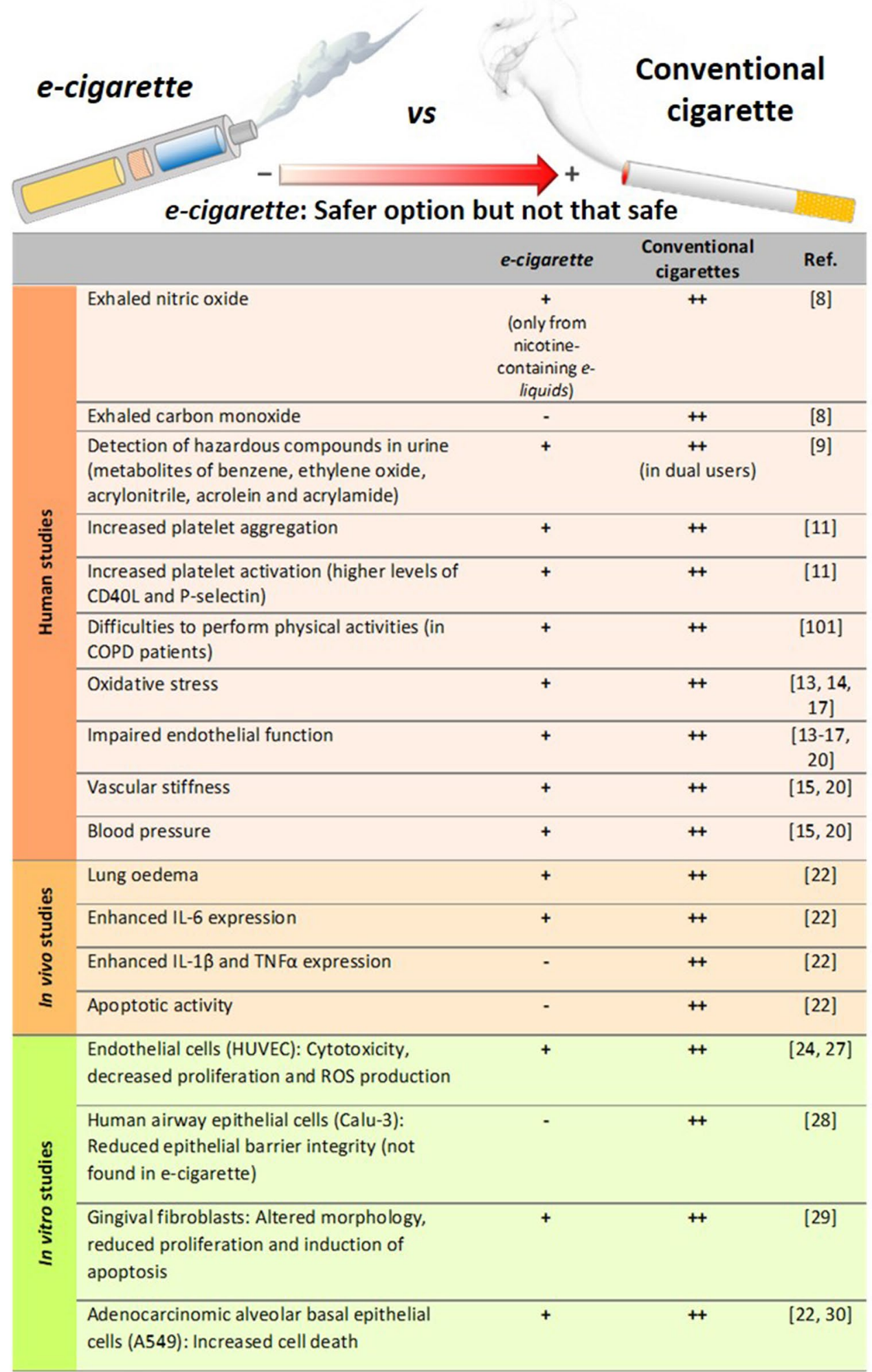

Fig. 2 Comparison of the degree of harmful effects documented from e-cigarette and conventional cigarette consumption. Human studies, in vivo mice exposure and in vitro studies. All of these effects from e-cigarettes were documented to be lower than those exerted by conventional cigarettes, which may suggest that e-cigarette consumption could be a safer option than conventional tobacco smoking but not a clear safe choice 
concentrations range from 0 ( $0 \%$, nicotine-free option) to $20 \mathrm{mg} / \mathrm{mL}(2.0 \%)$ - the maximum nicotine threshold according to directive 2014/40/EU of the European Parliament and the European Union Council [33, 34]. Despite this normative, however, some commercial e-liquids have nicotine concentrations close to $54 \mathrm{mg} / \mathrm{mL}$ [35], much higher than the limits established by the European Union.

The mislabelling of nicotine content in e-liquids has been previously addressed [8, 34]. For instance, gas chromatography with a flame ionisation detector (GC-FID) revealed inconsistencies in the nicotine content with respect to the manufacturer's declaration (average of $22 \pm 0.8 \mathrm{mg} / \mathrm{mL}$ vs. $18 \mathrm{mg} / \mathrm{mL}$ ) [8], which equates to a content $\sim 22 \%$ higher than that indicated in the product label. Of note, several studies have detected nicotine in those e-liquids labelled as nicotine-free $[5,35,36]$. One study detected the presence of nicotine $(0.11-6.90 \mathrm{mg} /$ $\mathrm{mL}$ ) in 5 of 23 nicotine-free labelled e-liquids by nuclear magnetic resonance spectroscopy [35], and another study found nicotine (average $8.9 \mathrm{mg} / \mathrm{mL}$ ) in $13.6 \%(17 / 125)$ of the nicotine-free e-liquids as analysed by high performance liquid chromatography (HPLC) [36]. Among the 17 samples tested in this latter study 14 were identified to be counterfeit or suspected counterfeit. A third study detected nicotine in 7 of 10 nicotine-free refills, although the concentrations were lower than those identified in the previous analyses $(0.1-15 \mu \mathrm{g} / \mathrm{mL})$ [5]. Not only is there evidence of mislabelling of nicotine content among refills labelled as nicotine-free, but there also seems to be a history of poor labelling accuracy in nicotine-containing e-liquids [37, 38].

A comparison of the serum levels of nicotine from e-cigarette or conventional cigarette consumption has been recently reported [39]. Participants took one vape from an e-cigarette, with at least $12 \mathrm{mg} / \mathrm{mL}$ of nicotine, or inhaled a conventional cigarette, every $20 \mathrm{~s}$ for $10 \mathrm{~min}$. Blood samples were collected 1, 2, 4, 6, 8, 10, 12 and $15 \mathrm{~min}$ after the first puff, and nicotine serum levels were measured by liquid chromatography-mass spectrometry (LC-MS). The results revealed higher serum levels of nicotine in the conventional CS group than in the e-cigarette group $(25.9 \pm 16.7 \mathrm{ng} / \mathrm{mL}$ vs. $11.5 \pm 9.8 \mathrm{ng} / \mathrm{mL})$. However, e-cigarettes containing $20 \mathrm{mg} / \mathrm{mL}$ of nicotine are more equivalent to normal cigarettes, based on the delivery of approximately $1 \mathrm{mg}$ of nicotine every $5 \mathrm{~min}$ [40].

In this line, a study compared the acute impact of CS vs. e-cigarette vaping with equivalent nicotine content in healthy smokers and non-smokers. Both increased markers of oxidative stress and decreased NO bioavailability, flow-mediated dilation, and vitamin $\mathrm{E}$ levels showing no significant differences between tobacco and e-cigarette exposure (reviewed in [20]). Inasmuch, short-term e-cigarette use in healthy smokers resulted in marked impairment of endothelial function and an increase in arterial stiffness (reviewed in [20]). Similar effects on endothelial dysfunction and arterial stiffness were found in animals when they were exposed to e-cigarette vapor either for several days or chronically (reviewed in [20]). In contrast, other studies found acute microvascular endothelial dysfunction, increased oxidative stress and arterial stiffness in smokers after exposure to $e$-cigarettes with nicotine, but not after e-cigarettes without nicotine (reviewed in [20]). In women smokers, a study found a significant difference in stiffness after smoking just one tobacco cigarette, but not after use of e-cigarettes (reviewed in [20]).

It is well known that nicotine is extremely addictive and has a multitude of harmful effects. Nicotine has significant biologic activity and adversely affects several physiological systems including the cardiovascular, respiratory, immunological and reproductive systems, and can also compromise lung and kidney function [41]. Recently, a sub-chronic whole-body exposure of e-liquid ( $2 \mathrm{~h}$ /day, 5 days/week, 30 days) containing PG alone or PG with nicotine $(25 \mathrm{mg} / \mathrm{mL})$ to wild type (WT) animals or knockout $(\mathrm{KO})$ mice in $\alpha 7$ nicotinic acetylcholine receptor (nAChR $\alpha 7-\mathrm{KO}$ ) revealed a partly nAChR $\alpha 7$ dependent lung inflammation [42]. While sub-chronic exposure to PG/nicotine promote $\mathrm{nAChR} \alpha 7$-dependent increased levels of different cytokines and chemokines in the bronchoalveolar lavage fluid (BALF) such as IL-1 $\alpha$, IL-2, IL-9, interferon $\gamma$ (IFN $\gamma$ ), granulocyte-macrophage colony-stimulating factor (GM-CSF), monocyte chemoattractant protein-1 (MCP-1/CCL2) and regulated on activation, normal $\mathrm{T}$ cell expressed and secreted (RANTES/CCL5), the enhanced levels of IL-1 $\beta$, IL-5 and $\mathrm{TNF} \alpha$ were $\mathrm{nAChR} \alpha 7$ independent. In general, most of the cytokines detected in BALF were significantly increased in WT mice exposed to PG with nicotine compared to PG alone or air control [42]. Some of these effects were found to be through nicotine activation of NF-kB signalling albeit in females but not in males. In addition, $\mathrm{PG}$ with nicotine caused increased macrophage and $\mathrm{CD} 4^{+} / \mathrm{CD}^{+}$T-lymphocytes cell counts in BALF compared to air control, but these effects were ameliorated when animals were sub-chronically exposed to PG alone [42].

Of note, another study indicated that although RANTES/CCL5 and CCR1 mRNA were upregulated in flavour/nicotine-containing e-cigarette users, vaping flavour and nicotine-less e-cigarettes did not significantly dysregulate cytokine and inflammasome activation [43].

In addition to its toxicological effects on foetus development, nicotine can disrupt brain development in adolescents and young adults [44-46]. Several studies have 
also suggested that nicotine is potentially carcinogenic (reviewed in [41]), but more work is needed to prove its carcinogenicity independently of the combustion products of tobacco [47]. In this latter regard, no differences were encountered in the frequency of tumour appearance in rats subjected to long-term (2 years) inhalation of nicotine when compared with control rats [48]. Despite the lack of carcinogenicity evidence, it has been reported that nicotine promotes tumour cell survival by decreasing apoptosis and increasing proliferation [49], indicating that it may work as a "tumour enhancer". In a very recent study, chronic administration of nicotine to mice ( $1 \mathrm{mg} / \mathrm{kg}$ every 3 days for a 60 -day period) enhanced brain metastasis by skewing the polarity of M2 microglia, which increases metastatic tumour growth [50]. Assuming that a conventional cigarette contains $0.172-$ $1.702 \mathrm{mg}$ of nicotine [51], the daily nicotine dose administered to these animals corresponds to 40-400 cigarettes for a $70 \mathrm{~kg}$-adult, which is a dose of an extremely heavy smoker. We would argue that further studies with chronic administration of low doses of nicotine are required to clearly evaluate its impact on carcinogenicity.

In the aforementioned study exposing human gingival fibroblasts to CS condensate or to nicotine-rich or nicotine-free e-vapour condensates [29], the detrimental effects were greater in cells exposed to nicotine-rich condensate than to nicotine-free condensate, suggesting that the possible injurious effects of nicotine should be considered when purchasing e-refills. It is also noteworthy that among the 3 most cytotoxic vapours for HUVEC evaluated in the Putzhammer et al. study, 2 were nicotine-free, which suggests that nicotine is not the only hazardous component in e-cigarettes [24].

The lethal dose of nicotine for an adult is estimated at 30-60 mg [52]. Given that nicotine easily diffuses from the dermis to the bloodstream, acute nicotine exposure by e-liquid spilling ( $5 \mathrm{~mL}$ of a $20 \mathrm{mg} / \mathrm{mL}$ nicotinecontaining refill is equivalent to $100 \mathrm{mg}$ of nicotine) can easily be toxic or even deadly [8]. Thus, devices with rechargeable refills are another issue of concern with e-cigarettes, especially when e-liquids are not sold in child-safe containers, increasing the risk of spilling, swallowing or breathing.

These data overall indicate that the harmful effects of nicotine should not be underestimated. Despite the established regulations, some inaccuracies in nicotine content labelling remain in different brands of e-liquids. Consequently, stricter regulation and a higher quality control in the e-liquid industry are required.

\section{Effect of humectants and their heating-related products} In this particular aspect, again the composition of the e-liquid varies significantly among different commercial brands $[4,35]$. The most common and major components of e-liquids are PG or 1,2-propanediol, and glycerol or glycerine (propane-1,2,3-triol). Both types of compounds are used as humectants to prevent the e-liquid from drying out $[2,53]$ and are classified by the Food and Drug Administration (FDA) as "Generally Recognised as Safe" [54]. In fact, they are widely used as alimentary and pharmaceutical products [2]. In an analysis of 54 commercially available e-liquids, PG and glycerol were detected in almost all samples at concentrations ranging from $0.4 \%$ to $98 \%$ (average $57 \%$ ) and from $0.3 \%$ to $95 \%$ (average $37 \%)$, respectively [35].

With regards to toxicity, little is known about the effects of humectants when they are heated and chronically inhaled. Studies have indicated that PG can induce respiratory irritation and increase the probability of asthma development $[55,56]$, and both PG and glycerol from e-cigarettes might reach concentrations sufficiently high to potentially cause irritation of the airways [57]. Indeed, the latter study established that one e-cigarette puff results in a PG exposure of $430-603 \mathrm{mg} / \mathrm{m}^{3}$, which is higher than the levels reported to cause airway irritation (average $309 \mathrm{mg} / \mathrm{m}^{3}$ ) based on a human study [55]. The same study established that one e-cigarette puff results in a glycerol exposure of $348-495 \mathrm{mg} / \mathrm{m}^{3}$ [57], which is close to the levels reported to cause airway irritation in rats $\left(662 \mathrm{mg} / \mathrm{m}^{3}\right)$ [58].

Airway epithelial injury induced by acute vaping of PG and glycerol aerosols (50:50 vol/vol), with or without nicotine, has been reported in two randomised clinical trials in young tobacco smokers [32]. In vitro, aerosols from glycerol only-containing refills showed cytotoxicity in A549 and human embryonic stem cells, even at a low battery output voltage [59]. PG was also found to affect early neurodevelopment in a zebrafish model [60]. Another important issue is that, under heating conditions PG can produce acetaldehyde or formaldehyde (119.2 or $143.7 \mathrm{ng} /$ puff at $20 \mathrm{~W}$, respectively, on average), while glycerol can also generate acrolein (53.0, 1000.0 or $5.9 \mathrm{ng} /$ puff at $20 \mathrm{~W}$, respectively, on average), all carbonyls with a well-documented toxicity [61]. Although, assuming 15 puffs per e-cigarette unit, carbonyls produced by PG or glycerol heating would be below the maximum levels found in a conventional cigarette combustion (Table 2) [51, 62]. Nevertheless, further studies are required to properly test the deleterious effects of all these compounds at physiological doses resembling those to which individuals are chronically exposed.

Although PG and glycerol are the major components of e-liquids other components have been detected. When the aerosols of 4 commercially available e-liquids chosen from a top 10 list of "Best E-Cigarettes of 2014", were analysed by gas chromatography-mass 
Table 2 Content comparison of the most common carbonyl compounds from e-cigarettes versus conventional tobacco cigarettes consumption

\begin{tabular}{llllll}
\hline & Formaldehyde $(\boldsymbol{\mu g})$ & Acetaldehyde $(\boldsymbol{\mu g})$ & & Acrolein $(\boldsymbol{\mu g})$ & References \\
\hline E-cigarette (unit $=15$ puffs) & $0.2-5.61$ & $0.11-1.36$ & $0.07-9$ & {$[4,68]$} \\
Conventional cigarette (unit) & $1.6-52.1$ & $52-828$ & $2.4-98.2$ & {$[51,62]$} \\
\hline
\end{tabular}

spectrometry (GC-MS) after heating, numerous compounds were detected, with nearly half of them not previously identified [4], thus suggesting that the heating process per se generates new compounds of unknown consequence. Of note, the analysis identified formaldehyde, acetaldehyde and acrolein [4], 3 carbonyl compounds with known high toxicity [63-67]. While no information was given regarding formaldehyde and acetaldehyde concentrations, the authors calculated that one puff could result in an acrolein exposure of 0.003$0.015 \mu \mathrm{g} / \mathrm{mL}$ [4]. Assuming $40 \mathrm{~mL}$ per puff and 15 puffs per e-cigarette unit (according to several manufacturers) [4], each e-cigarette unit would generate approximately 1.8-9 $\mu \mathrm{g}$ of acrolein, which is less than the levels of acrolein emitted by a conventional tobacco cigarette (18.3$98.2 \mu \mathrm{g}$ ) [51]. However, given that e-cigarette units of vaping are not well established, users may puff intermittently throughout the whole day. Thus, assuming 400 to 500 puffs per cartridge, users could be exposed to up to $300 \mu \mathrm{g}$ of acrolein.

In a similar study, acrolein was found in 11 of 12 aerosols tested, with a similar content range (approximately 0.07-4.19 $\mu$ g per e-cigarette unit) [68]. In the same study, both formaldehyde and acetaldehyde were detected in all of the aerosols tested, with contents of $0.2-5.61 \mu \mathrm{g}$ and $0.11-1.36 \mu \mathrm{g}$, respectively, per e-cigarette unit [68]. It is important to point out that the levels of these toxic products in e-cigarette aerosols are significantly lower than those found in CS: 9 times lower for formaldehyde, 450 times lower for acetaldehyde and 15 times lower for acrolein (Table 2) [62, 68].

Other compounds that have been detected in aerosols include acetamide, a potential human carcinogen [5], and some aldehydes [69], although their levels were minimal. Interestingly, the existence of harmful concentrations of diethylene glycol, a known cytotoxic agent, in e-liquid aerosols is contentious with some studies detecting its presence [4, 68, 70-72], and others finding low subtoxic concentrations [73, 74]. Similar observations were reported for the content ethylene glycol. In this regard, either it was detected at concentrations that did not exceed the authorised limit [73], or it was absent from the aerosols produced [4, 71, 72]. Only one study revealed its presence at high concentration in a very low number of samples [5]. Nevertheless, its presence above
$1 \mathrm{mg} / \mathrm{g}$ is not allowed by the FDA [73]. Figure 1 lists the main compounds detected in aerosols derived from humectant heating and their potential damaging effects. It would seem that future studies should analyse the possible toxic effects of humectants and related products at concentrations similar to those that e-cigarette vapers are exposed to reach conclusive results.

\section{Impact of flavouring compounds}

The range of e-liquid flavours available to consumers is extensive and is used to attract both current smokers and new e-cigarette users, which is a growing public health concern [6]. In fact, over 5 million middle- and high-school students were current users of e-cigarettes in 2019 [75], and appealing flavours have been identified as the primary reason for e-cigarette consumption in $81 \%$ of young users [76]. Since 2016, the FDA regulates the flavours used in the e-cigarette market and has recently published an enforcement policy on unauthorised flavours, including fruit and mint flavours, which are more appealing to young users [77]. However, the longterm effects of all flavour chemicals used by this industry (which are more than 15,000) remain unknown and they are not usually included in the product label [78]. Furthermore, there is no safety guarantee since they may harbour potential toxic or irritating properties [5].

With regards to the multitude of available flavours, some have demonstrated cytotoxicity $[59,79]$. Bahl et al. evaluated the toxicity of 36 different $e$-liquids and 29 different flavours on human embryonic stem cells, mouse neural stem cells and human pulmonary fibroblasts using a metabolic activity assay. In general, those e-liquids that were bubblegum-, butterscotch- and caramel-flavoured did not show any overt cytotoxicity even at the highest dose tested. By contrast, those e-liquids with Freedom Smoke Menthol Arctic and Global Smoke Caramel flavours had marked cytotoxic effects on pulmonary fibroblasts and those with Cinnamon Ceylon flavour were the most cytotoxic in all cell lines [79]. A further study from the same group [80] revealed that high cytotoxicity is a recurrent feature of cinnamon-flavoured e-liquids. In this line, results from GC-MS and HPLC analyses indicated that cinnamaldehyde (CAD) and 2-methoxycinnamaldehyde, but not dipropylene glycol or vanillin, were mainly responsible for the high cytotoxicity of 
cinnamon-flavoured e-liquids [80]. Other flavouringrelated compounds that are associated with respiratory complications [81-83], such as diacetyl, 2,3-pentanedione or acetoin, were found in 47 out of 51 aerosols of flavoured e-liquids tested [84]. Allen et al. calculated an average of $239 \mu \mathrm{g}$ of diacetyl per cartridge [84]. Assuming again 400 puffs per cartridge and $40 \mathrm{~mL}$ per puff, is it is possible to estimate an average of $0.015 \mathrm{ppm}$ of diacetyl per puff, which could compromise normal lung function in the long-term [85].

The cytotoxic and pro-inflammatory effects of different e-cigarette flavouring chemicals were also tested on two human monocytic cell lines-mono mac 6 (MM6) and U937 [86]. Among the flavouring chemicals tested, CAD was found to be the most toxic and O-vanillin and pentanedione also showed significant cytotoxicity; by contrast, acetoin, diacetyl, maltol, and coumarin did not show any toxicity at the concentrations assayed (10$1000 \mu \mathrm{M})$. Of interest, a higher toxicity was evident when combinations of different flavours or mixed equal proportions of e-liquids from 10 differently flavoured $e$-liquids were tested, suggesting that vaping a single flavour is less toxic than inhaling mixed flavours [86]. Also, all the tested flavours produced significant levels of ROS in a cell-free ROS production assay. Finally, diacetyl, pentanedione, O-vanillin, maltol, coumarin, and CAD induced significant IL-8 secretion from MM6 and U937 monocytes [86]. It should be borne in mind, however, that the concentrations assayed were in the supra-physiological range and it is likely that, once inhaled, these concentrations are not reached in the airway space. Indeed, one of the limitations of the study was that human cells are not exposed to e-liquids per se, but rather to the aerosols where the concentrations are lower [86]. In this line, the maximum concentration tested $(1000 \mu \mathrm{M})$ would correspond to approximately 80 to $150 \mathrm{ppm}$, which is far higher than the levels found in aerosols of some of these compounds [84]. Moreover, on a day-to-day basis, lungs of e-cigarette users are not constantly exposed to these chemicals for $24 \mathrm{~h}$ at these concentrations. Similar limitations were found when five of seven flavourings were found to cause cytotoxicity in human bronchial epithelial cells [87].

Recently, a commonly commercialized crème brûléeflavoured aerosol was found to contain high concentrations of benzoic acid (86.9 $\mu \mathrm{g} / \mathrm{puff})$, a well-established respiratory irritant [88]. When human lung epithelial cells (BEAS-2B and H292) were exposed to this aerosol for $1 \mathrm{~h}$, a marked cytotoxicity was observed in BEAS-2B but not in H292 cells, $24 \mathrm{~h}$ later. However, increased ROS production was registered in $\mathrm{H} 292$ cells [88].

Therefore, to fully understand the effects of these compounds, it is relevant the cell cultures selected for performing these assays, as well as the use of in vivo models that mimic the real-life situation of chronic e-cigarette vapers to clarify their impact on human health.

\section{The e-cigarette device}

While the bulk of studies related to the impact of $e$-cigarette use on human health has focused on the e-liquid components and the resulting aerosols produced after heating, a few studies have addressed the material of the electronic device and its potential consequences-specifically, the potential presence of metals such as copper, nickel or silver particles in e-liquids and aerosols originating from the filaments and wires and the atomiser [89-91].

Other important components in the aerosols include silicate particles from the fiberglass wicks or silicone [8991]. Many of these products are known to cause abnormalities in respiratory function and respiratory diseases [89-91], but more in-depth studies are required. Interestingly, the battery output voltage also seems to have an impact on the cytotoxicity of the aerosol vapours, with e-liquids from a higher battery output voltage showing more toxicity to A549 cells [30].

A recent study compared the acute effects of e-cigarette vapor (with PG/vegetable glycerine plus tobacco flavouring but without nicotine) generated from stainless-steel atomizer (SS) heating element or from a nickelchromium alloy (NC) [92]. Some rats received a single e-cigarette exposure for $2 \mathrm{~h}$ from a $\mathrm{NC}$ heating element $(60$ or $70 \mathrm{~W})$; other rats received a similar exposure of $e$-cigarette vapor using a SS heating element for the same period of time ( 60 or $70 \mathrm{~W}$ ) and, a final group of animals were exposed for $2 \mathrm{~h}$ to air. Neither the air-exposed rats nor those exposed to e-cigarette vapor using SS heating elements developed respiratory distress. In contrast, $80 \%$ of the rats exposed to $e$-cigarette vapor using $\mathrm{NC}$ heating units developed clinical acute respiratory distress when a $70-\mathrm{W}$ power setting was employed. Thus, suggesting that operating units at higher than recommended settings can cause adverse effects. Nevertheless, there is no doubt that the deleterious effects of battery output voltage are not comparable to those exerted by CS extracts [30] (Figs. 1 and 2).

\section{E-cigarettes as a smoking cessation tool}

CS contains a large number of substances-about 7000 different constituents in total, with sizes ranging from atoms to particulate matter, and with many hundreds likely responsible for the harmful effects of this habit [93]. Given that tobacco is being substituted in great part by e-cigarettes with different chemical compositions, manufacturers claim that e-cigarette will not cause lung diseases such as lung cancer, chronic obstructive pulmonary 
disease, or cardiovascular disorders often associated with conventional cigarette consumption [3, 94]. However, the World Health Organisation suggests that e-cigarettes cannot be considered as a viable method to quit smoking, due to a lack of evidence [7, 95]. Indeed, the results of studies addressing the use of e-cigarettes as a smoking cessation tool remain controversial [96-100]. Moreover, both FDA and CDC are actively investigating the incidence of severe respiratory symptoms associated with the use of vaping products [77]. Because many e-liquids contain nicotine, which is well known for its powerful addictive properties [41], e-cigarette users can easily switch to conventional cigarette smoking, avoiding smoking cessation. Nevertheless, the possibility of vaping nicotine-free e-cigarettes has led to the branding of these devices as smoking cessation tools $[2,6,7]$.

In a recently published randomised trial of 886 subjects who were willing to quit smoking [100], the abstinence rate was found to be twice as high in the e-cigarette group than in the nicotine-replacement group (18.0\% vs. 9.9\%) after 1 year. Of note, the abstinence rate found in the nicotine-replacement group was lower than what is usually expected with this therapy. Nevertheless, the incidence of throat and mouth irritation was higher in the e-cigarette group than in the nicotine-replacement group (65.3\% vs. $51.2 \%$, respectively). Also, the participant adherence to the treatment after 1-year abstinence was significantly higher in the e-cigarette group (80\%) than in nicotinereplacement products group (9\%) [100].

On the other hand, it is estimated that COPD could become the third leading cause of death in 2030 [101]. Given that COPD is generally associated with smoking habits (approximately 15 to $20 \%$ of smokers develop COPD) [101], smoking cessation is imperative among COPD smokers. Published data revealed a clear reduction of conventional cigarette consumption in COPD smokers that switched to e-cigarettes [101]. Indeed, a significant reduction in exacerbations was observed and, consequently, the ability to perform physical activities was improved when data was compared with those nonvapers COPD smokers. Nevertheless, a longer follow-up of these COPD patients is required to find out whether they have quitted conventional smoking or even vaping, since the final goal under these circumstances is to quit both habits.

Based on the current literature, it seems that several factors have led to the success of e-cigarette use as a smoking cessation tool. First, some $e$-cigarette flavours positively affect smoking cessation outcomes among smokers [102]. Second, e-cigarettes have been described to improve smoking cessation rate only among highlydependent smokers and not among conventional smokers, suggesting that the individual degree of nicotine dependence plays an important role in this process [97]. Third, the general belief of their relative harmfulness to consumers' health compared with conventional combustible tobacco [103]. And finally, the exposure to point-ofsale marketing of e-cigarette has also been identified to affect the smoking cessation success [96].

\section{Implication of e-cigarette consumption in COVID-19 time}

Different reports have pointed out that smokers and vapers are more vulnerable to SARS-CoV-2 (Severe Acute Respiratory Syndrome Coronavirus 2) infections or more prone to adverse outcomes if they suffer COVID-19 [104]. However, while a systematic review indicated that cigarette smoking is probably associated with enhanced damage from COVID-19, a meta-analysis did not, yet the latter had several limitations due to the small sample sizes [105].

Interestingly, most of these reports linking COVID19 harmful effects with smoking or vaping, are based on their capability of increasing the expression of angiotensin-converting enzyme 2 (ACE2) in the lung. It is well known that ACE2 is the gate for SARS-CoV-2 entrance to the airways [106] and it is mainly expressed in type 2 alveolar epithelial cells and alveolar macrophages [107]. To date, most of the studies in this field indicate that current smokers have higher expression of ACE2 in the airways (reviewed by [108]) than healthy non-smokers [109, 110]. However, while a recent report indicated that $e$-cigarette vaping also caused nicotine-dependent ACE2 upregulation [42], others have revealed that neither acute inhalation of e-cigarette vapour nor e-cigarette users had increased lung ACE2 expression regardless nicotine presence in the e-liquid $[43,110]$.

In regard to these contentions, current knowledge suggests that increased ACE2 expression is not necessarily linked to enhanced susceptibility to SARS-CoV-2 infection and adverse outcome. Indeed, elderly population express lower levels of ACE2 than young people and SARS-CoV-2/ACE2 interaction further decreases ACE2 expression. In fact, most of the deaths provoked by COVID-19 took place in people over 60 years old of age [111]. Therefore, it is plausible that the increased susceptibility to disease progression and the subsequent fatal outcome in this population is related to poor angiotensin 1-7 (Ang-1-7) generation, the main peptide generated by ACE2, and probably to their inaccessibility to its antiinflammatory effects. Furthermore, it seems that all the efforts towards increasing ACE2 expression may result in a better resolution of the pneumonic process associated to this pandemic disease.

Nevertheless, additional complications associated to COVID-19 are increased thrombotic events and cytokine storm. In the lungs, e-cigarette consumption has been 
Table 3 Future research needed in the impact of e-cigarette-consumption in human health

\begin{tabular}{l}
\hline Future research items to be addressed \\
\hline Evaluate long-term effects of e-cigarette-consumption in human health for safety guarantee \\
Search for clear evidences of e-cigarette as a smoking cessation tool \\
Increase the number of in vivo and ex vivo studies (preferentially in humans) \\
Study the effects of e-cigarette-consumption on the immune system \\
Study effects the impact of e-cigarette-consumption on the cardiovascular system \\
Analyse potential toxicological effects of humectants, flavourings and related products after the heating process at physiological concentrations (similar \\
to those that e-cigarette vapers are exposed) \\
Limit the number of flavourings authorised:The list should be strictly limited to those flavourings with long-term safety guaranteed, and appealing \\
flavours for children/adolescents should be banned \\
Eradicate counterfeit products and implement a stricter regulation (e.g., Establish a strict range of nicotine content worldwide; standardize labelling; \\
etc.) \\
Material device: all materials used should not generate harmful particles in aerosols \\
Follow-up study of the effects on respiratory and cardiovascular complications derived from SARS-CoV-2 infection
\end{tabular}

correlated to toxicity, oxidative stress, and inflammatory response [32, 112]. More recently, a study revealed that while the use of nicotine/flavour-containing e-cigarettes led to significant cytokine dysregulation and potential inflammasome activation, none of these effects were detected in non-flavoured and non-nicotine-containing e-cigarettes [43]. Therefore, taken together these observations, e-cigarette use may still be a potent risk factor for severe COVID-19 development depending on the flavour and nicotine content.

In summary, it seems that either smoking or nicotine vaping may adversely impact on COVID-19 outcome. However, additional follow up studies are required in COVID-19 pandemic to clarify the effect of e-cigarette use on lung and cardiovascular complications derived from SARS-CoV-2 infection.

\section{Conclusions}

The harmful effects of CS and their deleterious consequences are both well recognised and widely investigated. However, and based on the studies carried out so far, it seems that e-cigarette consumption is less toxic than tobacco smoking. This does not necessarily mean, however, that e-cigarettes are free from hazardous effects. Indeed, studies investigating their long-term effects on human health are urgently required. In this regard, the main additional studies needed in this field are summarized in Table 3.

The composition of e-liquids requires stricter regulation, as they can be easily bought online and many incidences of mislabelling have been detected, which can seriously affect consumers' health. Beyond their unknown long-term effects on human health, the extended list of appealing flavours available seems to attract new "never-smokers", which is especially worrying among young users. Additionally, there is still a lack of evidence of e-cigarette consumption as a smoking cessation method. Indeed, e-cigarettes containing nicotine may relieve the craving for smoking, but not the conventional cigarette smoking habit.

Interestingly, there is a strong difference of opinion on e-cigarettes between countries. Whereas countries such as Brazil, Uruguay and India have banned the sale of e-cigarettes, others such as the United Kingdom support this device to quit smoking. The increasing number of adolescent users and reported deaths in the United States prompted the government to ban the sale of flavoured e-cigarettes in 2020. The difference in opinion worldwide may be due to different restrictions imposed. For example, while no more than $20 \mathrm{ng} / \mathrm{mL}$ of nicotine is allowed in the EU, e-liquids with $59 \mathrm{mg} / \mathrm{dL}$ are currently available in the United States. Nevertheless, despite the national restrictions, users can easily access foreign or even counterfeit products online.

In regard to COVID-19 pandemic, the actual literature suggests that nicotine vaping may display adverse outcomes. Therefore, follow up studies are necessary to clarify the impact of e-cigarette consumption on human health in SARS-CoV-2 infection.

In conclusion, e-cigarettes could be a good alternative to conventional tobacco cigarettes, with less side effects; however, a stricter sale control, a proper regulation of the industry including flavour restriction, as well as further toxicological studies, including their chronic effects, are warranted.

\section{Abbreviations}

ACE2: Angiotensin-converting enzyme 2; Ang-1-7: Angiotensin 1-7; BALF: Bronchoalveolar lavage fluid; CAD: Cinnamaldehyde; CDC: US Centers for Disease Control and Prevention; CO: Carbon monoxide; COPD: Chronic obstructive pulmonary disease; COVID-19: Coronavirus disease 2019; CS: Cigarette 
smoke; ENDS: Electronic nicotine dispensing systems; EVALI: e-cigarette or vaping product use-associated lung injury; FDA: Food and Drug Administration; GC-FID: Gas chromatography with a flame ionisation detector; GC-MS: Gas chromatography-mass spectrometry; GM-CSF: Granulocyte-macrophage colony-stimulating factor; HPLC: High performance liquid chromatography; HUVEC: Human umbilical vein endothelial cells; IL: Interleukin; IFNY: Interferon ү; KO: Knockout; LC-MS: Liquid chromatography-mass spectrometry; MCP-1/ CCL2: Monocyte chemoattractant protein-1; MMP-9: Matrix metallopeptidase 9; nAChRa7: a7 Nicotinic acetylcholine receptor; NC: Nickel-chromium alloy; NO: Nitric oxide; PG: Propylene glycol; RANTES/CCL5: Regulated on activation, normal T cell expressed and secreted; ROS: Reactive oxygen species; SARSCoV-2: Severe acute respiratory syndrome coronavirus 2; SS: Stainless-steel atomizer; THC: Tetrahydrocannabinol; TNFa: Tumour necrosis factor-a; WT: Wild type.

\section{Acknowledgements}

The authors gratefully acknowledge Dr. Cruz González, Pulmonologist at University Clinic Hospital of Valencia (Valencia, Spain) for her thoughtful suggestions and support.

\section{Authors' contributions}

All authors discussed and agreed to the scope of the manuscript and contributed to the development of the manuscript at all stages. All authors read and approved the final manuscript.

\section{Funding}

This work was supported by the Spanish Ministry of Science and Innovation [Grant Number SAF2017-89714-R]; Carlos III Health Institute [Grant Numbers PIE15/00013, PI18/00209]; Generalitat Valenciana [Grant Number PROMETEO/2019/032, Gent T CDEI-04/20-A and AICO/2019/250], and the European Regional Development Fund.

\section{Availability of data and materials}

Not applicable.

\section{Declarations}

\section{Ethics approval and consent to participate}

Not applicable.

\section{Consent for publication}

Not applicable.

\section{Competing interests}

The authors of the manuscript declare no conflicts of interest and take sole responsibility for the writing and content of the manuscript. None of the authors have been involved in legal or regulatory matters related to the contents of this paper.

\section{Author details}

${ }^{1}$ Department of Pharmacology, Faculty of Medicine, University of Valencia, Avda. Blasco Ibañez 15, 46010 Valencia, Spain. ${ }^{2}$ Institute of Health Research INCLIVA, University Clinic Hospital of Valencia, Valencia, Spain. ${ }^{3}$ CIBERDEMSpanish Biomedical Research Centre in Diabetes and Associated Metabolic Disorders, ISCIII, Av. Monforte de Lemos 3-5, 28029 Madrid, Spain.

Received: 22 October 2020 Accepted: 3 May 2021

Published online: 18 May 2021

\section{References}

1. Hiemstra PS, Bals R. Basic science of electronic cigarettes: assessment in cell culture and in vivo models. Respir Res. 2016;17(1):127.

2. Bertholon JF, Becquemin MH, Annesi-Maesano I, Dautzenberg B. Electronic cigarettes: a short review. Respiration. 2013;86(5):433-8.

3. Rowell TR, Tarran R. Will chronic e-cigarette use cause lung disease? Am J Physiol Lung Cell Mol Physiol. 2015;309(12):L1398-409.

4. Herrington JS, Myers C. Electronic cigarette solutions and resultant aerosol profiles. J Chromatogr A. 2015;1418:192-9.
5. Hutzler C, Paschke M, Kruschinski S, Henkler F, Hahn J, Luch A. Chemical hazards present in liquids and vapors of electronic cigarettes. Arch Toxicol. 2014:88(7):1295-308.

6. Pokhrel P, Herzog TA, Muranaka N, Fagan P. Young adult e-cigarette users' reasons for liking and not liking e-cigarettes: a qualitative study. Psychol Health. 2015;30(12):1450-69.

7. Harrell PT, Simmons VN, Correa JB, Padhya TA, Brandon TH. Electronic nicotine delivery systems ("e-cigarettes"): review of safety and smoking cessation efficacy. Otolaryngol Head Neck Surg. 2014;151(3):381-93.

8. Schober W, Szendrei K, Matzen W, Osiander-Fuchs H, Heitmann D, Schettgen $T$, et al. Use of electronic cigarettes (e-cigarettes) impairs indoor air quality and increases FeNO levels of e-cigarette consumers. Int J Hyg Environ Health. 2014;217(6):628-37.

9. Rubinstein ML, Delucchi K, Benowitz NL, Ramo DE. Adolescent exposure to toxic volatile organic chemicals from E-cigarettes. Pediatrics. 2018;141(4):e20173557.

10. Staudt MR, Salit J, Kaner RJ, Hollmann C, Crystal RG. Altered lung biology of healthy never smokers following acute inhalation of E-cigarettes. Respir Res. 2018;19(1):78.

11. Nocella C, Biondi-Zoccai G, Sciarretta S, Peruzzi M, Pagano F, Loffredo L, et al. Impact of tobacco versus electronic cigarette smoking on platelet function. Am J Cardiol. 2018;122(9):1477-81.

12. Higham A, Rattray NJW, Dewhurst JA, Trivedi DK, Fowler SJ, Goodacre $R$, et al. Electronic cigarette exposure triggers neutrophil inflammatory responses. Respir Res. 2016;17(1):56.

13. Antoniewicz L, Bosson JA, Kuhl J, Abdel-Halim SM, Kiessling A, Mobarrez $F$, et al. Electronic cigarettes increase endothelial progenitor cells in the blood of healthy volunteers. Atherosclerosis. 2016;255:179-85.

14. Carnevale R, Sciarretta S, Violi F, Nocella C, Loffredo L, Perri L, et al. Acute impact of tobacco vs electronic cigarette smoking on oxidative stress and vascular function. Chest. 2016:150(3):606-12.

15. Vlachopoulos C, loakeimidis N, Abdelrasoul M, Terentes-Printzios D, Georgakopoulos C, Pietri $\mathrm{P}$, et al. Electronic cigarette smoking increases aortic stiffness and blood pressure in young smokers. J Am Coll Cardiol. 2016:67(23):2802-3.

16. Franzen KF, Willig J, Cayo Talavera S, Meusel M, Sayk F, Reppel M, et al. E-cigarettes and cigarettes worsen peripheral and central hemodynamics as well as arterial stiffness: a randomized, double-blinded pilot study. Vasc Med. 2018;23(5):419-25.

17. Caporale A, Langham MC, Guo W, Johncola A, Chatterjee S, Wehrli FW. Acute effects of electronic cigarette aerosol inhalation on vascular function detected at quantitative MRI. Radiology. 2019:293(1):97-106.

18. von Hundelshausen P, Schmitt MM. Platelets and their chemokines in atherosclerosis-clinical applications. Front Physiol. 2014;5:294.

19. Landmesser $U$, Hornig B, Drexler $\mathrm{H}$. Endothelial function: a critical determinant in atherosclerosis? Circulation. 2004;109(21 Suppl 1):li27-33.

20. Münzel T, Hahad O, Kuntic M, Keaney JF, Deanfield JE, Daiber A. Effects of tobacco cigarettes, e-cigarettes, and waterpipe smoking on endothelial function and clinical outcomes. Eur Heart J. 2020;41:4057-70.

21. Javelle E. Electronic cigarette and vaping should be discouraged during the new coronavirus SARS-CoV-2 pandemic. Arch Toxicol. 2020;94(6):2261-2.

22. Husari A, Shihadeh A, Talih S, Hashem Y, El Sabban M, Zaatari G. Acute exposure to electronic and combustible cigarette aerosols: effects in an animal model and in human alveolar cells. Nicotine Tob Res. 2016:18(5):613-9.

23. Zelikoff JT, Parmalee NL, Corbett K, Gordon T, Klein CB, Aschner M Microglia activation and gene expression alteration of neurotrophins in the hippocampus following early-life exposure to E-cigarette aerosols in a murine model. Toxicol Sci. 2018;162(1):276-86.

24. Putzhammer R, Doppler C, Jakschitz T, Heinz K, Forste J, Danzl K, et al. Vapours of US and EU market leader electronic cigarette brands and liquids are cytotoxic for human vascular endothelial cells. PLoS One. 2016;11(6):e0157337.

25. Bernhard D, Pfister G, Huck CW, Kind M, Salvenmoser W, Bonn GK, et al. Disruption of vascular endothelial homeostasis by tobacco smoke: impact on atherosclerosis. Faseb J. 2003;17(15):2302-4.

26. Newby DE, Wright RA, Labinjoh C, Ludlam CA, Fox KA, Boon NA, et al. Endothelial dysfunction, impaired endogenous fibrinolysis, and 
cigarette smoking: a mechanism for arterial thrombosis and myocardial infarction. Circulation. 1999;99(11):1411-5.

27. Taylor M, Jaunky T, Hewitt K, Breheny D, Lowe F, Fearon IM, et al. A comparative assessment of e-cigarette aerosols and cigarette smoke on in vitro endothelial cell migration. Toxicol Lett. 2017;277:123-8.

28. Herr C, Tsitouras K, Niederstraßer J, Backes C, Beisswenger C, Dong L, et al. Cigarette smoke and electronic cigarettes differentially activate bronchial epithelial cells. Respir Res. 2020;21(1):67.

29. Alanazi H, Park HJ, Chakir J, Semlali A, Rouabhia M. Comparative study of the effects of cigarette smoke and electronic cigarettes on human gingival fibroblast proliferation, migration and apoptosis. Food Chem Toxicol. 2018;118:390-8.

30. Otreba M, Kosmider L. E-cigarettes: voltage- and concentrationdependent loss in human lung adenocarcinoma viability. J Appl Toxicol. 2018;38(8):1135-43.

31. Chaumont M, Bernard A, Pochet S, Melot C, El Khattabi C, Reye F, et al. High-wattage E-cigarettes induce tissue hypoxia and lower airway injury: a randomized clinical trial. Am J Respir Crit Care Med. 2018;198(1):123-6.

32. Chaumont M, van de Borne P, Bernard A, Van Muylem A, Deprez G, Ullmo J, et al. Fourth generation e-cigarette vaping induces transient lung inflammation and gas exchange disturbances: results from two randomized clinical trials. Am J Physiol Lung Cell Mol Physiol. 2019;316(5):L705-19.

33. European Parliament and the council of the European Union. Directive 2014/40/EU. 2014 (updated April 29, 2014). https://ec.europa.eu/healt h//sites/health/files/tobacco/docs/dir_201440_en.pdf. Accessed 17 April 2020.

34. Cameron JM, Howell DN, White JR, Andrenyak DM, Layton ME, Rol $J \mathrm{M}$. Variable and potentially fatal amounts of nicotine in e-cigarette nicotine solutions. Tob Control. 2014;23(1):77-8.

35. Hahn J, Monakhova YB, Hengen J, Kohl-Himmelseher M, Schussler J, Hahn $\mathrm{H}$, et al. Electronic cigarettes: overview of chemical composition and exposure estimation. Tob Induc Dis. 2014;12(1):23.

36. Omaiye EE, Cordova I, Davis B, Talbot P. Counterfeit electronic cigarette products with mislabeled nicotine concentrations. Tob Regul Sci. 2017;3(3):347-57

37. Buettner-Schmidt K, Miller DR, Balasubramanian N. Electronic cigarette refill liquids: child-resistant packaging, nicotine content, and sales to minors. J Pediatr Nurs. 2016;31(4):373-9.

38. Jackson R, Huskey M, Brown S. Labelling accuracy in low nicotine e-cigarette liquids from a sampling of US manufacturers. Int J Pharm Pract. 2019;28(3):290-4.

39. Yingst JM, Foulds J, Veldheer S, Hrabovsky S, Trushin N, Eissenberg $T T$, et al. Nicotine absorption during electronic cigarette use among regular users. PLoS One. 2019;14(7):e0220300.

40. Farsalinos KE, Romagna G, Tsiapras D, Kyrzopoulos S, Voudris V. Evaluation of electronic cigarette use (vaping) topography and estimation of liquid consumption: implications for research protocol standards definition and for public health authorities'regulation. Int J Environ Res Public Health. 2013;10(6):2500-14.

41. Mishra A, Chaturvedi P, Datta S, Sinukumar S, Joshi P, Garg A. Harmful effects of nicotine. Indian J Med Paediatr Oncol. 2015;36(1):24-31.

42. Wang Q, Sundar IK, Li D, Lucas JH, Muthumalage T, McDonough SR, et al. E-cigarette-induced pulmonary inflammation and dysregulated repair are mediated by nAChR a7 receptor: role of nAChR a7 in SARSCoV-2 Covid-19 ACE2 receptor regulation. Respir Res. 2020;21 (1):154

43. Lee AC, Chakladar J, Li WT, Chen C, Chang EY, Wang-Rodriguez J, et al. Tobacco, but not nicotine and flavor-less electronic cigarettes, induces ACE2 and immune dysregulation. Int J Mol Sci. 2020;21(15):5513.

44. England LJ, Bunnell RE, Pechacek TF, Tong VT, McAfee TA. Nicotine and the developing human: a neglected element in the electronic cigarette debate. Am J Prev Med. 2015;49(2):286-93.

45. Yuan M, Cross SJ, Loughlin SE, Leslie FM. Nicotine and the adolescent brain. J Physiol. 2015;593(16):3397-412.

46. Holbrook BD. The effects of nicotine on human fetal development. Birth Defects Res C Embryo Today. 2016;108(2):181-92.

47. Sanner T, Grimsrud TK. Nicotine: carcinogenicity and effects on response to cancer treatment-a review. Front Oncol. 2015;5:196.

48. Waldum HL, Nilsen OG, Nilsen T, Rørvik H, Syversen V, Sanvik AK, et al. Long-term effects of inhaled nicotine. Life Sci. 1996;58(16):1339-46.
49. Cucina A, Dinicola S, Coluccia P, Proietti S, D'Anselmi F, Pasqualato A, et al. Nicotine stimulates proliferation and inhibits apoptosis in colon cancer cell lines through activation of survival pathways. J Surg Res. 2012;178(1):233-41.

50. Wu SY, Xing F, Sharma S, Wu K, Tyagi A, Liu Y, et al. Nicotine promotes brain metastasis by polarizing microglia and suppressing innate immune function. J Exp Med. 2020;217(8):e20191131.

51. Roemer E, Stabbert R, Rustemeier K, Veltel DJ, Meisgen TJ, Reininghaus W, et al. Chemical composition, cytotoxicity and mutagenicity of smoke from US commercial and reference cigarettes smoked under two sets of machine smoking conditions. Toxicology. 2004;195(1):31-52.

52. Mayer B. How much nicotine kills a human? Tracing back the generally accepted lethal dose to dubious self-experiments in the nineteenth century. Arch Toxicol. 2014;88(1):5-7.

53. Brown CJ, Cheng JM. Electronic cigarettes: product characterisation and design considerations. Tob Control. 2014;23(Suppl 2):ii4-10.

54. Food and Drug Administration. SCOGS (Select Committee on GRAS Substances). 2019 (updated April 29, 2019). https://www.accessdata. $\mathrm{fda.gov/scripts/fdcc/index.cfm?set=SCOGS \& sort=Sortsubstance \&}$ order=ASC\&startrow $=251 \&$ type $=$ basic\&search $=$. Accessed 14 April 2020.

55. Wieslander G, Norback D, Lindgren T. Experimental exposure to propylene glycol mist in aviation emergency training: acute ocular and respiratory effects. Occup Environ Med. 2001;58(10):649-55.

56. Choi H, Schmidbauer N, Sundell J, Hasselgren M, Spengler J, Bornehag CG. Common household chemicals and the allergy risks in pre-school age children. PLoS One. 2010;5(10):e13423.

57. Kienhuis AS, Soeteman-Hernandez LG, Bos PMJ, Cremers HWJM, Klerx WN, Talhout R. Potential harmful health effects of inhaling nicotine-free shisha-pen vapor: a chemical risk assessment of the main components propylene glycol and glycerol. Tob Induc Dis. 2015;13(1):15.

58. Renne RA, Wehner AP, Greenspan BJ, Deford HS, Ragan HA, Westerberg RB, et al. 2-Week and 13-week inhalation studies of aerosolized glycerol in rats. Inhal Toxicol. 1992;4(2):95-111.

59. Behar R, Wang Y, Talbot P. Comparing the cytotoxicity of electronic cigarette fluids, aerosols and solvents. Tob Control. 2018;27(3):325.

60. Massarsky A, Abdel A, Glazer L, Levin ED, Di Giulio RT. Neurobehavioral effects of 1,2-propanediol in zebrafish (Danio rerio). Neurotoxicology. 2018;65:111-24.

61. Geiss O, Bianchi I, Barrero-Moreno J. Correlation of volatile carbonyl yields emitted by e-cigarettes with the temperature of the heating coil and the perceived sensorial quality of the generated vapours. Int J Hyg Environ Health. 2016;219(3):268-77.

62. Counts ME, Morton MJ, Laffoon SW, Cox RH, Lipowicz PJ. Smoke composition and predicting relationships for international commercial cigarettes smoked with three machine-smoking conditions. Regul Toxicol Pharmacol. 2005;41(3):185-227.

63. Agency for Toxic Substances \& Disease Registry. Toxicological Profile for Formaldehyde. 2019 (updated September 26, 2019). https://www.atsdr. cdc.gov/ToxProfiles/tp.asp?id=220\&tid=39. Accessed 9 April 2020.

64. Agency for Toxic Substances \& Disease Registry. Toxicological Profile for Acrolein. 2019 (updated September 26, 2019). https://www.atsdr.cdc. gov/toxprofiles/TP.asp?id=557\&tid=102. Accessed 9 April 2020

65. Moghe A, Ghare S, Lamoreau B, Mohammad M, Barve S, McClain C, et al. Molecular mechanisms of acrolein toxicity: relevance to human disease. Toxicol Sci. 2015;143(2):242-55.

66. Seitz HK, Stickel F. Acetaldehyde as an underestimated risk factor for cancer development: role of genetics in ethanol metabolism. Genes Nutr. 2010;5(2):121-8.

67. Faroon O, Roney N, Taylor J, Ashizawa A, Lumpkin MH, Plewak DJ. Acrolein health effects. Toxicol Ind Health. 2008;24(7):447-90.

68. Goniewicz ML, Knysak J, Gawron M, Kosmider L, Sobczak A, Kurek J, et al. Levels of selected carcinogens and toxicants in vapour from electronic cigarettes. Tob Control. 2014;23(2):133-9.

69. Farsalinos KE, Voudris V. Do flavouring compounds contribute to aldehyde emissions in e-cigarettes? Food Chem Toxicol. 2018;115:212-7.

70. Kavvalakis MP, Stivaktakis PD, Tzatzarakis MN, Kouretas D, Liesivuori J, Alegakis AK, et al. Multicomponent analysis of replacement liquids of electronic cigarettes using chromatographic techniques. J Anal Toxicol. 2015:39(4):262-9. 
71. Etter JF, Zather E, Svensson S. Analysis of refill liquids for electronic cigarettes. Addiction. 2013;108(9):1671-9.

72. Etter JF, Bugey A. E-cigarette liquids: constancy of content across batches and accuracy of labeling. Addict Behav. 2017;73:137-43.

73. Varlet V, Farsalinos K, Augsburger M, Thomas A, Etter JF. Toxicity assessment of refill liquids for electronic cigarettes. Int J Environ Res Public Health. 2015;12(5):4796-815.

74. McAuley TR, Hopke PK, Zhao J, Babaian S. Comparison of the effects of e-cigarette vapor and cigarette smoke on indoor air quality. Inhal Toxicol. 2012;24(12):850-7.

75. Cullen KA, Gentzke AS, Sawdey MD, Chang JT, Anic GM, Wang TW, et al. e-Cigarette use among youth in the United States, 2019. JAMA 2019;322(21):2095-103.

76. Villanti AC, Johnson AL, Ambrose BK, Cummings KM, Stanton CA, Rose SW, et al. Flavored tobacco product use in youth and adults: findings from the first wave of the PATH Study (2013-2014). Am J Prev Med. 2017;53(2):139-51.

77. Food and Drug Administration. Vaporizers, E-Cigarettes, and other Electronic Nicotine Delivery Systems (ENDS) 2020 (updated April 13, 2020) https://www.fda.gov/tobacco-products/products-ingredients-compo nents/vaporizers-e-cigarettes-and-other-electronic-nicotine-deliverysystems-ends. Accessed 15 April 2020

78. Omaiye EE, McWhirter KJ, Luo W, Tierney PA, Pankow JF, Talbot P. High concentrations of flavor chemicals are present in electronic cigarette refill fluids. Sci Rep. 2019;9(1):2468.

79. Bahl V, Lin S, Xu N, Davis B, Wang YH, Talbot P. Comparison of electronic cigarette refill fluid cytotoxicity using embryonic and adult models. Reprod Toxicol. 2012;34(4):529-37.

80. Behar R, Davis B, Wang Y, Bahl V, Lin S, Talbot P. Identification of toxicants in cinnamon-flavored electronic cigarette refill fluids. Toxicol In Vitro. 2014:28(2):198-208.

81. Morgan DL, Flake GP, Kirby PJ, Palmer SM. Respiratory toxicity of diacetyl in C57BL/6 mice. Toxicol Sci. 2008;103(1):169-80.

82. Hubbs AF, Cumpston AM, Goldsmith WT, Battelli LA, Kashon ML, Jackson MC, et al. Respiratory and olfactory cytotoxicity of inhaled 2,3-pentanedione in Sprague-Dawley rats. Am J Pathol. 2012;181(3):829-44.

83. Vas CA, Porter A, Mcadam K. Acetoin is a precursor to diacetyl in e-cigarette liquids. Food Chem Toxicol. 2019:133:110727.

84. Allen JG, Flanigan SS, LeBlanc M, Vallarino J, MacNaughton P, Stewart $\mathrm{JH}$, et al. Flavoring chemicals in E-cigarettes: diacetyl, 2,3-pentanedione, and acetoin in a sample of 51 products, including fruit-, candy-, and cocktail-flavored E-cigarettes. Environ Health Perspect. 2016;124(6):733-9.

85. Park RM, Gilbert SJ. Pulmonary impairment and risk assessment in a diacetyl-exposed population: microwave popcorn workers. J Occup Environ Med. 2018;60(6):496-506.

86. Muthumalage T, Prinz M, Ansah KO, Gerloff J, Sundar IK, Rahman I. Inflammatory and oxidative responses induced by exposure to commonly used e-cigarette flavoring chemicals and flavored e-liquids without nicotine. Front Physiol. 2017;8:1130.

87. Sherwood CL, Boitano S. Airway epithelial cell exposure to distinc e-cigarette liquid flavorings reveals toxicity thresholds and activation of CFTR by the chocolate flavoring 2,5-dimethypyrazine. Respir Res. 2016;17(1):57.

88. Pinkston R, Zaman H, Hossain E, Penn AL, Noël A. Cell-specific toxicity of short-term JUUL aerosol exposure to human bronchial epithelial cells and murine macrophages exposed at the air-liquid interface. Respir Res. 2020:21(1):269.

89. Williams M, Villarreal A, Bozhilov K, Lin S, Talbot P. Metal and silicate particles including nanoparticles are present in electronic cigarette cartomizer fluid and aerosol. PLoS One. 2013;8(3):e57987.

90. Mikheev VB, Brinkman MC, Granville CA, Gordon SM, Clark PI. Real-time measurement of electronic cigarette aerosol size distribution and metals content analysis. Nicotine Tob Res. 2016;18(9):1895-902.

91. Williams M, Bozhilov K, Ghai S, Talbot P. Elements including metals in the atomizer and aerosol of disposable electronic cigarettes and electronic hookahs. PLoS One. 2017;12(4):e0175430.

92. Kleinman MT, Arechavala RJ, Herman D, Shi J, Hasen I, Ting A, et al. E-cigarette or vaping product use-associated lung injury produced in an animal model from electronic cigarette vapor exposure without tetrahydrocannabinol or vitamin E oil. J Am Heart Assoc. 2020;9(18):e017368.

93. Patnode CD, Henderson JT, Thompson JH, Senger CA, Fortmann SP, Whitlock EP. Behavioral counseling and pharmacotherapy interventions for tobacco cessation in adults, including pregnant women: a review of reviews for the U.S. preventive services task force. Ann Intern Med. 2015;163(8):608-21.

94. Messner B, Bernhard D. Smoking and cardiovascular disease: mechanisms of endothelial dysfunction and early atherogenesis. Arterioscler Thromb Vasc Biol. 2014;34(3):509-15.

95. Bansal V, Kim K-H. Review on quantitation methods for hazardous pollutants released by e-cigarette (EC) smoking. Trends Analyt Chem. 2016;78:120-33.

96. Mantey DS, Pasch KE, Loukas A, Perry CL. Exposure to point-of-sale marketing of cigarettes and E-cigarettes as predictors of smoking cessation behaviors. Nicotine Tob Res. 2019;21(2):212-9.

97. Selya AS, Dierker L, Rose JS, Hedeker D, Mermelstein RJ. The role of nicotine dependence in E-cigarettes' potential for smoking reduction. Nicotine Tob Res. 2018;20(10):1272-7.

98. Kalkhoran S, Glantz SA. E-cigarettes and smoking cessation in realworld and clinical settings: a systematic review and meta-analysis. Lancet Respir Med. 2016;4(2):116-28.

99. Levy DT, Yuan Z, Luo Y, Abrams DB. The relationship of e-cigarette use to cigarette quit attempts and cessation: insights from a large, nationally representative U.S. survey. Nicotine Tob Res. 2017;20(8):931-9.

100. Hajek P, Phillips-Waller A, Przulj D, Pesola F, Myers Smith K, Bisal N, et al. A randomized trial of $\mathrm{E}$-cigarettes versus nicotine-replacement therapy. N Engl J Med. 2019;380(7):629-37.

101. Polosa R, Morjaria JB, Caponnetto P, Prosperini U, Russo C, Pennisi A, et al. Evidence for harm reduction in COPD smokers who switch to electronic cigarettes. Respir Res. 2016;17(1):166.

102. Litt MD, Duffy V, Oncken C. Cigarette smoking and electronic cigarette vaping patterns as a function of e-cigarette flavourings. Tob Control. 2016;25(Suppl 2):ii67-72.

103. Palmer AM, Brandon TH. How do electronic cigarettes affect cravings to smoke or vape? Parsing the influences of nicotine and expectancies using the balanced-placebo design. J Consult Clin Psychol. 2018:86(5):486-91.

104. Majmundar A, Allem JP, Cruz TB, Unger JB. Public health concerns and unsubstantiated claims at the intersection of vaping and COVID-19. Nicotine Tob Res. 2020;22(9):1667-8.

105. Berlin I, Thomas D, Le Faou A-L, Cornuz J. COVID-19 and smoking Nicotine Tob Res. 2020;22(9):1650-2.

106. Wrapp D, Wang N, Corbett KS, Goldsmith JA, Hsieh C-L, Abiona O, et al. Cryo-EM structure of the 2019-nCoV spike in the prefusion conformation. Science. 2020;367(6483):1260-3.

107. Wang K, Gheblawi M, Oudit GY. Angiotensin Converting Enzyme 2: A Double-Edged Sword. Circulation. 2020;142(5):426-8.

108. Sharma P, Zeki AA. Does vaping increase susceptibility to COVID-19? Am J Respir Crit Care Med. 2020;202(7):1055-6.

109. Brake SJ, Barnsley K, Lu W, McAlinden KD, Eapen MS, Sohal SS. Smoking upregulates angiotensin-converting enzyme-2 receptor: a potential adhesion site for novel coronavirus SARS-CoV-2 (Covid-19). J Clin Med. 2020;9(3):841.

110. Zhang H, Rostamim MR, Leopold PL, Mezey JG, O'Beirne SL, StruloviciBarel Y, et al. Reply to sharma and zeki: does vaping increase susceptibility to COVID-19? Am J Respir Crit Care Med. 2020;202(7):1056-7.

111. Cheng $H$, Wang $Y$, Wang GQ. Organ-protective effect of angiotensinconverting enzyme 2 and its effect on the prognosis of COVID-19. J Med Virol. 2020;92(7):726-30.

112. Lerner CA, Sundar IK, Yao H, Gerloff J, Ossip DJ, Mclntosh S, et al. Vapors produced by electronic cigarettes and e-juices with flavorings induce toxicity, oxidative stress, and inflammatory response in lung epithelial cells and in mouse lung. PLoS ONE. 2015:10(2):e0116732

\section{Publisher's Note}

Springer Nature remains neutral with regard to jurisdictional claims in published maps and institutional affiliations. 